\title{
Educação, Linguagem e Diversidades: saberes interdisciplinares em diálogo
}

O Dossiê que temos a satisfação de apresentar ao público leitor da Cadernos de Gênero e Diversidade trata-se de uma organização por docentes do Programa de Pós-Graduação em Educação, Linguagem e Tecnologias - PPG IELT - da Universidade Estadual de Goiás e tem como objetivo divulgar pesquisas e saberes produzidos, em parceria entre orientadores/as e orientandos/as, na disciplina Educação $e$ Diversidades do Programa, ofertada no segundo semestre de 2019. A referida disciplina tem por objetivo geral refletir sobre o papel sociocultural da universidade e da escola enquanto instituições formadoras responsáveis pela promoção de uma educação voltada para as minorias, ou seja, de uma educação para as diversidades e para a valorização da cultura nas suas diferentes interfaces, especialmente, da linguagem. De modo específico, almeja também: a) compreender as dimensões pertinentes à educação inclusiva, educação especial e ao binômio educação e diversidade, bem como sua incidência na sociedade atual e nos contextos escolares; b) problematizar as responsabilidades individuais e coletivas envolvidas em uma educação ética para as diversidades, alteridade, multiculturalidade, interculturalidade crítica e inter/transdisciplinaridade, considerando a importância dos processos interacionais em contextos escolares formais e não formais; c) discutir temas relativos à escola inclusiva e para minorias, como as questões étnico-raciais, de gênero, orientação sexual e enfrentamento da violência nas/das instituições de ensino e em outros contextos sociais; d) refletir sobre as linguagens em contextos diversos, ou seja, interculturais, como nas comunidades indígenas, quilombolas, imigrantes, de fronteiras e outras; e) analisar criticamente os documentos legais de orientação sobre direitos humanos, inclusão e diversidades a fim de mapear a trajetória histórica das políticas públicas para as diversidades no Brasil, principalmente a partir da década de 90.

Assim, o Dossiê Educação, Linguagem e Diversidades: saberes interdisciplinares em diálogo está em consonância com o perfil, foco e escopo da Cadernos de Gênero e Diversidade, uma vez que congrega 11 textos que discutem a temática da Diversidade, revelada em diferentes 
nuances em cada texto que o constitui. Cada autor/a e seus/suas coautores/as, imbuídos/as do desejo de apresentar suas percepções do ato de escrever também como um ato solidário e de resistência, em tempos de pandemia, de isolamento social e de silenciamento das questões de gênero, raça/etnia, sexualidades, inclusão, transdisciplinaridade e interculturalidade crítica, entre outros espectros que contemplam os estudos das diversidades, o fazem por acreditar que os direitos humanos precisam fazer valer os direitos das pessoas minorizadas e marginalizadas em nosso país e no mundo. Ademais, comungamos com Freire (2010, p. 26) de que "os educandos vão se transformando em reais sujeitos da construção e da reconstrução do saber ensinado, ao lado do educador, igualmente sujeito do processo". Desse modo, três principais eixos dentro do amplo escopo dos estudos das Diversidades, interseccionados com as áreas de Educação e de Linguagem, balizam as discussões dos artigos deste Dossiê: 1) "Gênero, raça e sexualidades: problematizações em educação, direitos humanos, linguagens e literatura", composto por três textos; 2) "Inclusão e diversidades: problematizações em cenários educacionais", composto por cinco textos; 3) "Transdisciplinaridade, translinguagem e interculturalidade crítica: problematizações em educação linguística e formação docente", composto por três textos. A seguir, apresentamos cada um desses textos, organizados sequencialmente conforme os eixos indicados.

No artigo que abre o Dossiê, de título Onde estão as pessoas trans?: narrativas sobre corporalidades dissidentes em espaço escolar, Renan Nogueira e Hélvio Frank trazem à reflexão as narrativas de Riana, uma mulher que se declara transexual, a fim de problematizar suas corporalidades dissidentes localizadas em contexto escolar. Inscrita no paradigma qualitativo e interpretativo, sob perspectiva narrativa em Linguística Aplicada Crítica, a pesquisa mostra que a escola é espaço da diversidade e que precisa ir além da reprodução e manutenção como reprodutor social da exclusão, das convenções binárias e problematizar as padronizações que buscam evidenciar as diferenças a fim de excluí-las das normas estabelecidas pela sociedade. Em uma interpretação balizada por estudos queer, os autores destacam ainda que o contexto escolar, por meio da mediação docente e a descolonização dos currículos, tem o potencial de propor mudanças no tratamento das comunidades diversas.

Na sequência, Edergênio Vieira, em Interseccionalidades de raça, gênero, machismo e sexismo na literatura insurgente de Lima 
Barreto, nos oferece uma viagem literária, musical, pop, idiossincrática e sub-reptícia por um caminho que explora suas subjetividades como homem, negro, professor, morador de periferia e militante social com duas obras literárias do escritor Lima Barreto: "Clara dos Anjos" e "Recordações do Escrivão Isaías Caminha", evidenciando as interseccionalidades de raça, gênero, machismo e sexismo presentes nos romances. Para tanto, o autor coloca-se o desafio de construir novas possibilidades transgressivas e insurgentes na escrita acadêmica, optando por configurar seu texto em uma linguagem caleidoscópica e intersecionada, analisando e problematizando vários temas que se fragmentam nos recortes específicos e que se unem para formar um todo. Nesse sentido, sua escritura funciona como um fluxo de pensamento, na qual insere também links de músicas/clips citadas. Além disso, Vieira nomeia as seções do texto com letras de rap que guardam relação com o assunto debatido naqueles espaços. É, sem dúvidas, um texto problematizador e instigante.

Em Pluralizando o gênero e desestabilizando as normas inteligíveis através de uma "leitura diferente", José Ariosvaldo Alixandrino e Ariovaldo Lopes Pereira abordam a diversidade e a pluralidade de performances de gênero, fazendo um contraponto à crença dominante de que há apenas uma possibilidade de performance, aquela baseada na cis-heteronormatividade, o que torna as formas "diferentes" de performar gênero invisíveis ou minorizadas. Para tanto, os autores advogam em favor da necessidade de se pensar o gênero num viés crítico, para que as pessoas possam conhecer e se posicionar de forma consciente e ativa frente aos pré-conceitos da sociedade. Dentre as formas possíveis de reflexão, discutem algumas leituras literárias que problematizam as matrizes inteligíveis cis-heteronormalizadoras e, assim, abrem espaço para se questionar essa normatização, reconhecendo e legitimando as identidades de gênero que a transgridem. Um detalhe importante que ressaltamos do texto de Alixandrino e Pereira é a escolha pela problematização da temática de gênero a partir de obras literárias que, via de regra, atendem ao público infanto-juvenil, um nicho de estudos ainda pouco explorado.

$\mathrm{O}$ artigo Inclusão na Educação Superior: uma reflexão sobre as diretrizes curriculares nacionais vigentes, das autoras Norma Maria Passos Vargas e Marlene Barbosa de Freitas Reis, tem como objetivo compreender como a legislação relativa à educação inclusiva na Educação Superior contribui no sentido de oferecer subsídios legais para 
a permanência e conclusão da graduação do aluno com alguma deficiência. Para tanto, as autoras utilizaram da pesquisa bibliográfica e documental. O estudo aponta que, embora tenham sido criadas diversas políticas públicas no sentido de incluir pessoas com alguma deficiência na Educação Superior, ainda não é possível garantir a permanência e atendimento das mesmas devido a diversos desafios enfrentados.

Já o artigo Educação Inclusiva nas Políticas de Avaliação Institucional: Reflexos no contexto da Universidade Estadual de Goiás, de Diessyka F. Monteiro e Yara Fonseca de Oliveira e Silva, trata das diretrizes para a educação inclusiva no ensino superior e seu reflexo no planejamento, avaliação e resultados da autoavaliação institucional realizada na Universidade Estadual de Goiás. Na tentativa de realizar a crítica e apontar sugestões, o estudo realizado aplicou a metodologia de análise documental do Relatório Consolidado de autoavaliação do ciclo trienal (2015-2017) produzido pela Comissão Própria de Avaliação CPA/UEG com base no Plano de Desenvolvimento Institucional - PDI (2010-2019). Concluiu-se que as diretrizes que conduziram a elaboração da Lei Brasileira de Inclusão da Pessoa com Deficiência foram parcialmente agregadas às políticas de avaliação institucional da instituição investigada.

No artigo Atendimento Educacional Especializado (AEE): educação inclusiva para e pela diversidade, Daniela Gonçalves Mendonça Nordony, Franciele Virgínia da Silva Carvalho e Luciana Ribeiro Alves Vieira expõem um estudo de caso, tendo como principal referência relatos de experiência de uma professora do Atendimento Educacional Especializado de uma Instituição de Ensino de Educação Infantil, na cidade de Anápolis - GO. Como resultado dessa reflexão ficou evidente a emergente necessidade de mudanças paradigmáticas do modelo educacional para que práticas de inclusão sejam consolidadas, sobretudo a partir da formação continuada de professores/as.

Em Inclusão escolar e nomenclaturas para pessoas com deficiência: Algumas reflexões com professores de Damolândia - GO, Jéssica Hilário Pinto e Gláucia Vieira Cândido apresentam um estudo sobre o uso de nomenclaturas atribuídas às pessoas com deficiência no decorrer dos anos no contexto educacional brasileiro. As autoras discutem as concepções de profissionais envolvidos/as no ensino inclusivo acerca de suas concepções ao adotarem determinados termos lexicais. Os resultados revelam que, no contexto pesquisado, apesar de os princípios de inclusão terem propiciado a criação de diversas leis e 
decretos, ainda é preciso refletir muito sobre o tema. Nesse sentido, evidencia-se também a necessidade de políticas públicas que visem a dar uma nova dinâmica aos discursos e práticas educacionais inclusivas vigentes.

$\mathrm{O}$ artigo $O$ Atendimento Educacional Especializado no processo de inclusão de alunos com deficiência na escola regular, de autoria de Cássia A. P. Silva e Leonor Paniago Rocha, versa sobre a legislação que busca garantir as condições de acesso, acessibilidade e permanência dos/ as alunos/as com deficiência, transtornos globais do desenvolvimento e altas habilidades ou superdotação, que frequentam a sala de ensino regular comum e o Atendimento Educacional Especializado (AEE). Por meio de uma abordagem bibliográfica, as autoras se embasaram em sete documentos oficiais que tratam da temática da inclusão. Nesse estudo, Silva e Rocha defendem que a implementação do AEE nas escolas pode causar angústias e esperanças, mas acima de tudo mudança e possibilidade de efetivação de uma educação verdadeiramente inclusiva.

Camila da Rocha Lobo e João Henrique Suanno, no artigo Reformar o pensamento ao formar educadores: um desafio na educação, abordam a formação docente com uma abordagem baseada na ruptura do paradigma tradicional e na reforma do pensamento para abertura da pluralidade de saberes, diante de exigências que, a todo momento, se renovam na educação. Para tal, há a necessidade de compreender a diversidade e as visões diferentes de mundo. Portanto, a autora e o autor nos desvelam os desafios encontrados na formação de professores no que concerne à reforma de pensamento diante da diversidade na educação, e nos contam que, à luz do pensamento complexo, não há barreiras e padrões normativos para um educar com qualidade. Lobo e Suanno argumentam que, indiscutivelmente, urge uma mudança nos moldes da formação docente, pois a padronização, a falta de alteridade e a intolerância das diferenças não se mostram um caminho aceitável para se percorrer na busca por uma educação de qualidade e inclusiva. Esperam que o estudo que desenvolveram seja mais um adendo propulsor na preocupação de se formar educadores/as para o plural.

Em Translinguagem e interculturalidade na educação linguística crítica: entre concepções e articulações, Jossane Oliveira e Barbra Sabota discutem algumas concepções teóricas sobre língua e translinguagem, buscando traçar uma relação com a interculturalidade no cenário da educação linguística crítica. O principal intento das 
autoras é, a partir de seus locais de fala, problematizar esses termos e compreender em que medida eles se relacionam, propondo alguns exercícios de mobilização de saberes dentro da perspectiva de educação linguística crítica. Nesse sentido, o texto de Oliveira e Sabota contribui para a percepção de que língua e cultura são indissociáveis para o processo de educação linguística crítica. Trata-se, assim, de um texto que sucita problematizações caras a uma proposta de educação linguística que vislumbre mudanças sociais.

Encerra o Dossiê o artigo Interculturalidade crítica e educação linguística: problematizando (des)invenções, assinado por Michael Rodrigues e Viviane Silvestre. A partir do entendimento de que as invenções são construções sociais e que apenas se consolidam por meio de crenças e verdades (com)partilhadas, o autor e a autora discutem como certas invenções, especificamente aquelas ligadas à colonização linguística e cultural, ainda reverberam por meio de colonialidades que condicionam nosso modo de agir e conceber o mundo e nós mesmos/as. De modo específico, buscam suspeitar sobre como a noção de interculturalidade tem sido inventada no campo de educação linguística e quais poderiam ser vias alternativas de sua (des)invenção. As problematizações trazidas por Rodrigues e Silvestre apontam para a interculturalidade crítica como alternativa de (des)invenção no campo de educação linguística, advinda de bases epistemológicas suleadas. É um texto que nos instiga (re)pensar os conceitos de língua e interculturalidade, de modo a perceber o potencial político do campo de educação linguística.

Notamos, então, que o conjunto de textos que compõem este Dossiê engloba diferentes facetas do diálogo interdisciplinar entre Educação, Linguagem e Diversidades. Em um país não apenas diverso, mas extremamente desigual como o nosso, reflexões como essas se fazem prementes. Não podemos deixar de ressaltar o momento sócio-histórico de pandemia da COVID-19 que marca a publicação deste Dossiê, momento esse em que as desigualdades se tornam ainda mais escancaradas e, por isso mesmo, precisam ser combatidas em movimentos de enfrentamento. As mudanças bruscas e o impacto causado em todas as dimensões do nosso cotidiano, inclusive no processo de produção de conhecimentos, são anúncios de uma educação ancorada no coletivo e em ações concretas do contexto histórico-social vigente que nos leva a pensar o mundo humano para além das fronteiras do mundo geográfico e que se constitui na relação dialética entre 
objetividade e subjetividade (Freire, 2010). Por isso, ao trazermos à tona os três eixos de discussão que sustentam os artigos do presente Dossiê Gênero, raça e sexualidades: problematizações em educação, direitos humanos, linguagens e literatura, Inclusão e diversidades: problematizações em cenários educacionais e Transdisciplinaridade, translinguagem e interculturalidade crítica: problematizações em educação linguística e formação docente - esperamos contribuir nesse movimento.

Por fim, reiteramos a relevância desta parceria entre o PPG IELT/UEG e a Cadernos de Gênero e Diversidade, agradecendo a contribuição de cada autor e autora dos artigos e, de modo especial, a generosidade da comissão editorial da revista em acolher nossa proposta e em acreditar, assim como nós, que, "se estamos a favor da vida e não da morte, da equidade e não da injustiça, do direito e não do arbítrio, da convivência com o diferente e não de sua negação, não temos outro caminho senão viver plenamente a nossa opção" (FREIRE, 2001, p. 31-32). Almejamos que os textos que compõem este Dossiê se tornem referência para outros estudos interdisciplinares envolvidos com questões de diversidade em nosso país. Desejamos uma inspiradora leitura acreditando que "não é no silêncio que os homens se fazem, mas na palavra, no trabalho, na ação-reflexão" (FREIRE, 2002, p. 78).

Marlene Barbosa de Freitas REIS Viviane Pires Viana SILVESTRE João Henrique SUANNO

\section{Referências}

FREIRE, Paulo. Educação como prática da liberdade. 25a. ed. São Paulo: Paz e Terra, 2001.

FREIRE, Paulo. Pedagogia do oprimido. 34a. ed. São Paulo: Paz e Terra, 2002.

FREIRE, Paulo. Pedagogia da autonomia: saberes necessários à prática docente. São Paulo: Paz e Terra, 2010. 